\title{
Analysis of fuel consumption of a spark ignition engine in the conditions of a variable load
}

\author{
Andrzej Bieniek ${ }^{1, *}$, Mariusz Graba ${ }^{1}$, Krystian Hennek ${ }^{1}$, and Jarosław Mamala ${ }^{1}$ \\ ${ }^{1}$ Opole University of Technology, ul. Proszkowska 76, 45-758 Opole, Poland
}

\begin{abstract}
This paper reports the results of a study into operating parameters of an system consisting of an SI engine and a drivertrain in a Fiat Panda passenger car in the conditions of a variable load. The analysis was primarily concerned with the variability of fuel consumption resulting of the changing load applied to the driving wheels in the conditions of a test performed on dynamometer rollers. The bench test included a dedicated driving cycle in which a constant linear speed of the car was changed every $10 \mathrm{~km} / \mathrm{h}$ and subsequently maintained for registration and analysis purposes. The focus of the study involved the identification of the points characterized with the minimum specific fuel consumption. Throughout the test, the load applied to the transmission was alternated by simulating an increase of road inclination for which the variability of the engine efficiency was analyzed.
\end{abstract}

\section{Introduction}

Despite the considerable media noise focusing on the developments in electric powertrains, throughout the many years to come, we can expect further development of vehicle powertrains powered by traditional combustion engines. At present, engine designs are continuously improved with the purpose of fulfilling ever stricter emission standards, including $\mathrm{CO}_{2}$ emissions, which are directly relative to the fuel consumption [1-3]. The developmental tests that are considered to be particularly interesting include studies into variable power output resulting from the application of Variable Compression Ratio (VCR) and Controlled Auto-Ignition (CAI). However, the complete exploitation of the operating parameters of such up-todate engine designs is only possible by the application of powertrain systems with a considerable capability of torque transfer. Concurrently, we know that the factor representing the utilization of the installed power is relative to the integration of the Driver-VehicleEnvironment (DVE) model. Although the role of the driver is to decide on the demanded linear car velocity in a free or induced manner, this is already largely limited in modern powertrains. In this context, the adequately selected traction characteristic of the vehicle should provide a high efficiency of the overall system. However, the efficiency of the engine varies depending on the position of the acceleration pedal, and this is due to the fact that it is utilized in variable ambient conditions - including rain, wind, snow or variable terrain. Problems in these areas lead to the small efficiency of the use of engine power, in particular during drive on a low gear and extremely variable linear vehicle speeds during urban drive.
The research reported in this paper was undertaken with the purpose of a detailed analysis of the impact of variable engine load on the fuel consumption of a passenger car. The variable load in this paper refers to the increase of road inclination angle expressed in per cent for the particular gearbox ratios. As a result of the additional load of the driving wheels (and thus, a variable load of the powertrain of a passenger car), the fuel use is known is increase. The testing procedure was performed on a Maha MSR 500 chassis dynamometer by application of a test car.

\section{Measurement methodology}

The analysis of fuel consumption of the conditions of the variable engine load was performed on the basis of the research conducted on a MAHA MSR 500 chassis dynamometer installed at the Department of Road and Agricultural Vehicles, Opole University of Technology. The testing applied Fiat Panda passenger car with the engine capacity $1242 \mathrm{~cm}^{3}$ and a maximum power of 44 kW (Fig. 1).

A dedicated driving cycle was defined for the purposes of the research with a section involving a constant linear car velocity for each of the gearbox ratios. The range of the linear vehicle velocity was selected individually for each of the gears so that the rotational speed can be changed in the range from 1000 $\mathrm{rpm}$ to $5500 \mathrm{rpm}$. The linear velocity was increased stepwise by $10 \mathrm{~km} / \mathrm{h}$ and the velocity profile followed in the driving cycle is presented in Fig. 2.

Throughout the duration of the test, the car was in motion at a constant linear car velocity and the gearbox ratio was given in accordance with the cycle described above. In addition, the scope of the study involved the

*Corresponding author: a.bieniek@po.opole.pl 
change of the additional load of the powertrain associated with the simulated variation in the road inclination. The basic study was conducted for the car rolling on a horizontal surface and, subsequently, simulation tests were repeated for the $3 \%, 5 \%, 7 \%$ and $10 \%$ road inclinations.

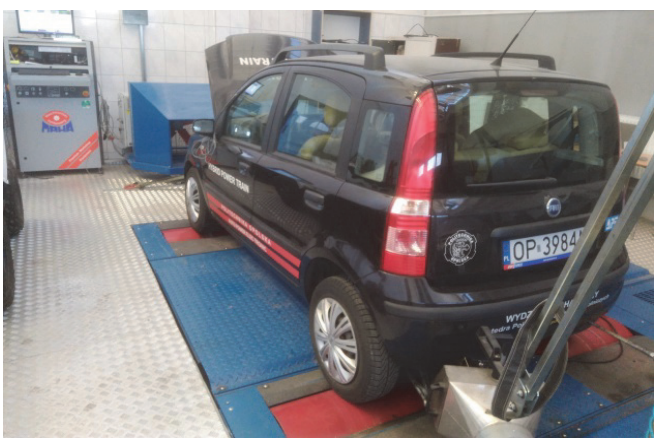

Fig. 1. Test bench.

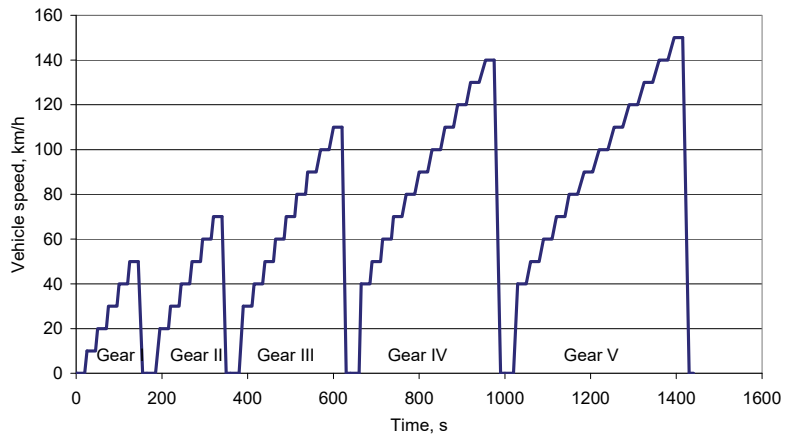

Fig. 2. Course of the driving cycle.

The testing procedure was accompanied by the measurements of fuel consumption undertaken with Flowtronic 215 fuel measuring system accompanied by pollutant emission measurement by means of MGT 5 analyzer. The analysis applied averaged data registered at the given points (for a constant car velocity) throughout the driving cycle. Exemplary results of actual registrations made by the measuring system are presented in Fig. 3.

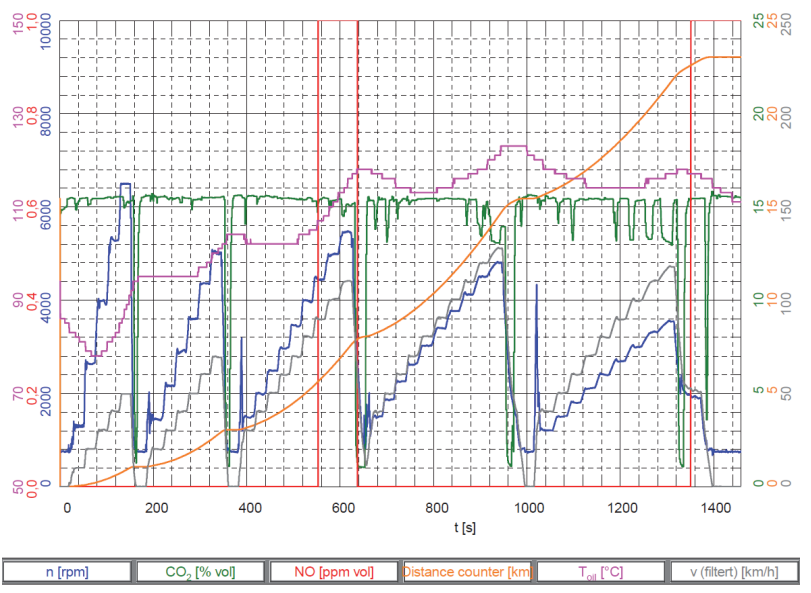

Fig. 3. Examples of data registered by the dynamometer system for $3 \%$ road inclination.
For each of the registered cycles, the measuring system of the dynamometer recorded 11 variables accompanied by fuel consumption measurement by the system indicated above.

\section{Fuel consumption during constant car}

The literature in the area of fundamentals of vehicle dynamics $[4,5]$ gives that driving force acting on a car in the conditions of its acceleration or rolling at a constant speed, we have to do with an equilibrium resulting from the resistance to motion, consisting of rolling resistance, drag forces, climbing resistance and inertia forces resulting from the car acceleration.

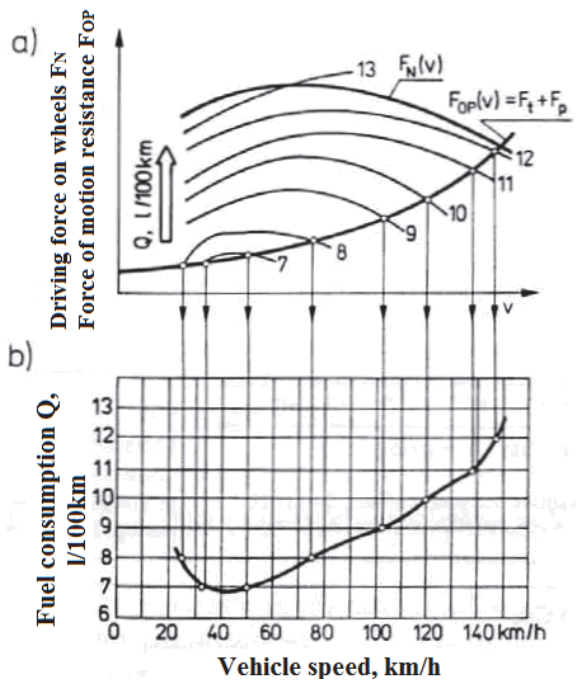

Fig. 4. Fuel consumption for a constant car velocity [5].

The figure above represents the theoretical description of the characteristic of fuel consumption for a constant car velocity. The points in Fig. 4a define the characteristics of the instantaneous equilibrium of the transmission system, where the driving force is balanced by the forces acting on the car. In such conditions, the total of values of the basic resistive forces, including rolling resistance $F_{t}$, drag force $F_{P}$, climbing resistance $F_{W}$ have to compensate the driving force and the formula of motion states that at such an operating point the car acceleration is close to zero.

$$
\frac{d v}{d t}=\frac{F_{N}-\left(F_{t p}+F_{w}\right)}{m \delta}
$$

where: $m$ - mass of car, $F_{N}$ - driving force on wheels, $F_{T P}$ - total rolling and air resistance on the horizontal road, $F_{W}$ - resistance of the road inclination, $\delta-$ spin mass coefficient.

Given the simplifications above, for a constant linear car velocity, we can perform an analysis of the course of the driving force in a car powertrain in an experimental manner by following adequate procedures during road test. However, we need to bear in mind that it is beneficial to perform all these activities during a single road test, whose course should be similar to the standard driving maneuvers performed by a driver throughout an 
actual road drive. However, since it is difficult to perform such a test during actual drive, there is a possibility of performing an analysis on a chassis dynamometer comprising electrodynamic brakes acting on the particular driven axles in a vehicle. In such conditions, it is possible to apply approximate forces representing resistance to motion to the vehicle powertrain and analyze the engine response in the form of variations in fuel consumption. Based on the insights from literature, we know that the increase of the engine load resulting from is climbing, in turn leads to an increased fuel consumption.

\section{Variable load of the powertrain}

The variable load of the transmission in a car is realized by application of an electrodynamic brake to the drive axle. The registered driving force acting on the dynamometer rollers is formed by the product of the driving force output and the linear car velocity. On the basis of the conducted studies, we have undertaken an analysis of the course of the power generated by the engine, and an exemplary power curve for a given constant load (for $3 \%$ road inclination) and variable linear car velocity corresponding to the particular gearbox ratios is presented in Fig. 5.

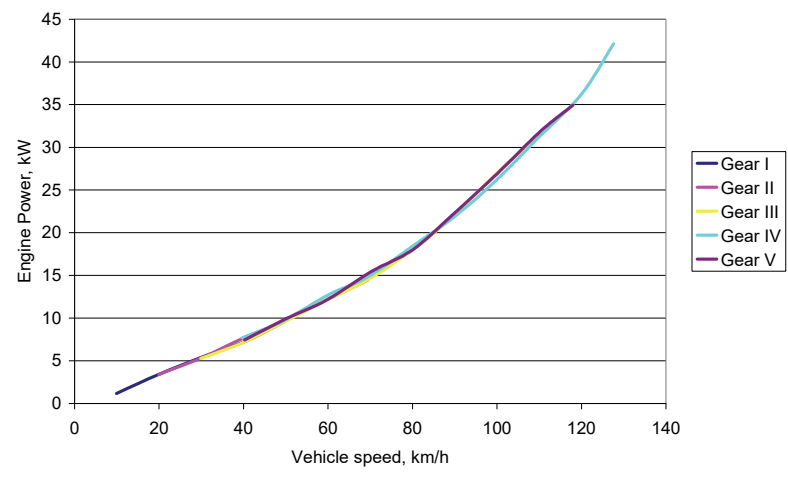

Fig. 5. Course of engine power for $3 \%$ road inclination.

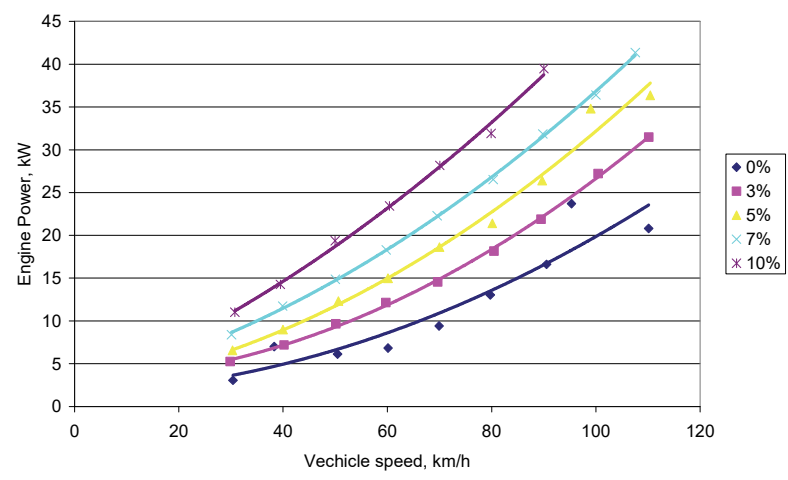

Fig. 6. Course of the engine power for 3 rd gear corresponding to various road inclinations.

The engine power measured in the powertrain is in range of the forecasted results (Fig. 4). However, within the range of the constant ratio in the 3rd gear, the variability of the engine power is already considerable during the changing road inclination, as presented in Fig. 6. The change in the road inclination from $0 \%$ to $10 \%$ leads to almost 2.5 times increase of the engine power. Concurrently, in the conditions of $10 \%$ road inclination, the car is not capable of developing an output adequate to accelerate the car to the demanded constant velocity specified in the driving cycle. This condition was registered for 3rd gear (partly), as well as 4th and 5th gears. We also noted that a two times increase of the engine power is necessary to overcome a road inclination of $7 \%$ for the $3 \mathrm{rd}$ gear, for which fuel consumption was also registered.

An analysis of the fuel consumption was performed, whose level also increases two times for the car speeds of 40 and $60 \mathrm{~km} / \mathrm{h}$, however, for greater speeds, it decreases and the engine power output approaches the peak value.

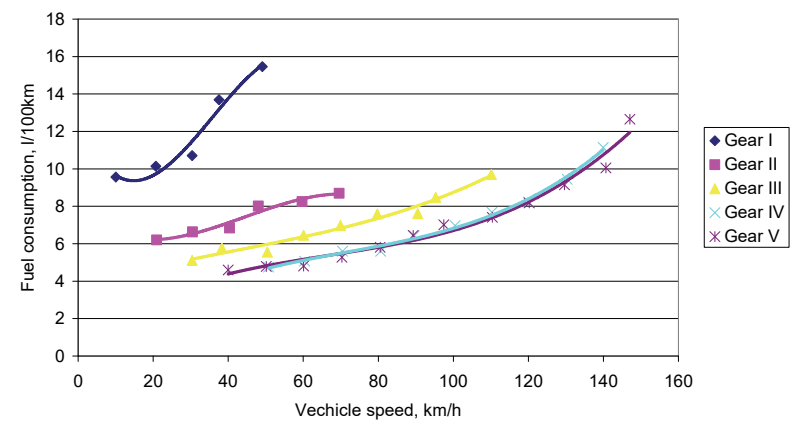

Fig. 7. Distance-based fuel consumption for a constant gearbox ratio and $0 \%$ road inclination.

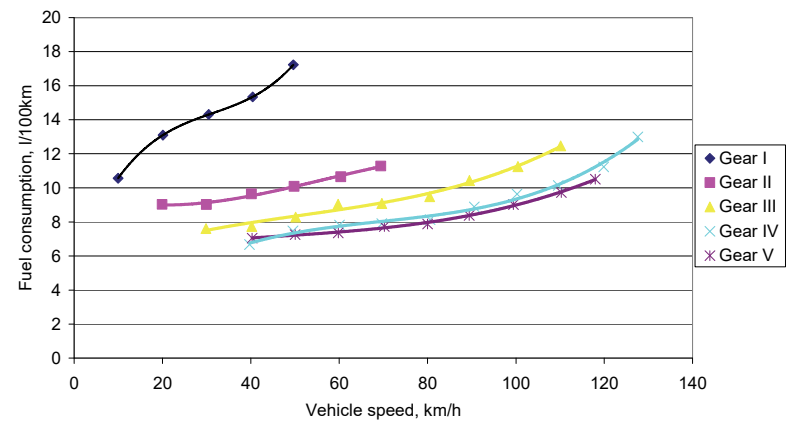

Fig. 8. Distance-based fuel consumption for a constant gearbox ratio and $3 \%$ road inclination.

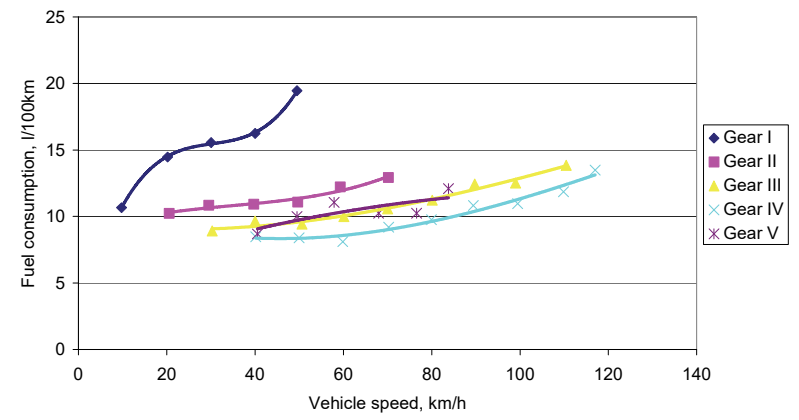

Fig. 9. Distance-based fuel consumption for a constant gearbox ratio and $5 \%$ road inclination. 


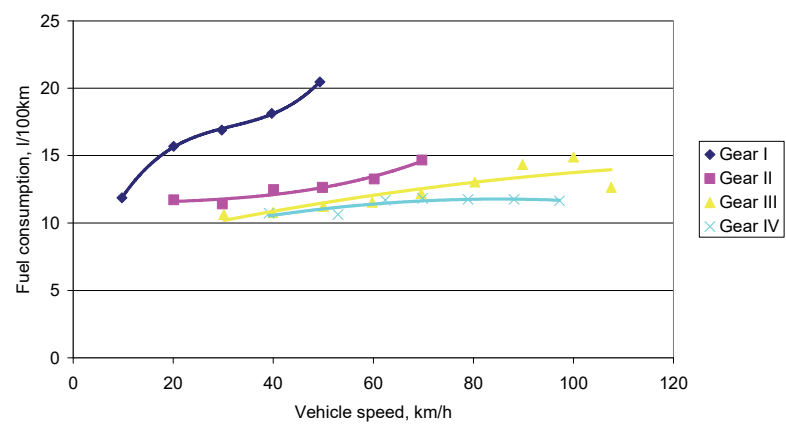

Fig. 10. Distance-based fuel consumption for a constant gearbox ratio and $7 \%$ road inclination.

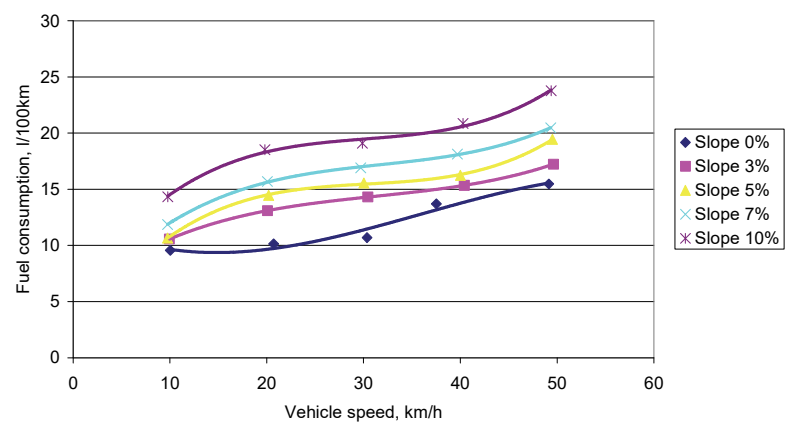

Fig. 11. Distance-based fuel consumption for gear I and variable road inclination.
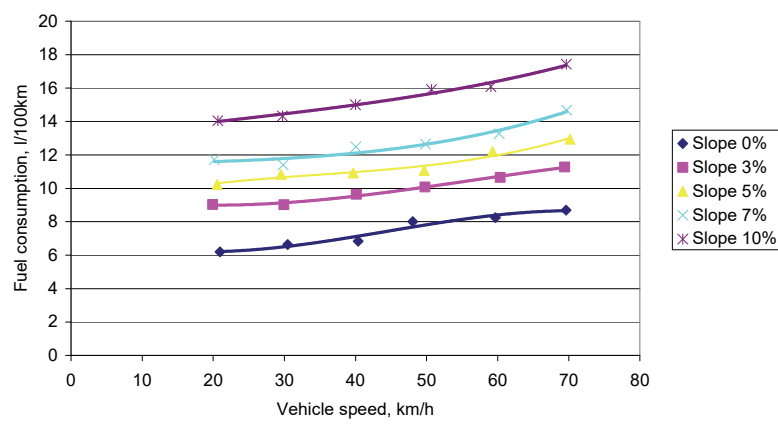

Fig. 12. Distance-based fuel consumption for gear II and variable road inclination.

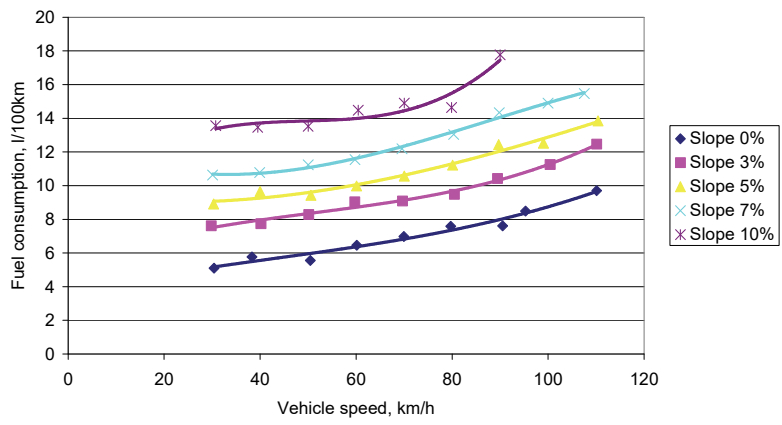

Fig. 13. Distance-based fuel consumption for gear III and variable road inclination.

The engine characteristic does not always include a minimum fuel consumption based on the criterion of the distance driven, as given in [6-8], and this fact was also observed with regard to the examined engine and confirmed on its characteristic. This is quite standard with regard to engines with a sequential multi-point fuel injection. Concurrently, very important differences can be noted for the case when the distance-based fuel consumption is converted into flow rate of fuel supply and the result is presented in the function of the rotational speed of the engine crankshaft, as presented on Fig. 15-18.

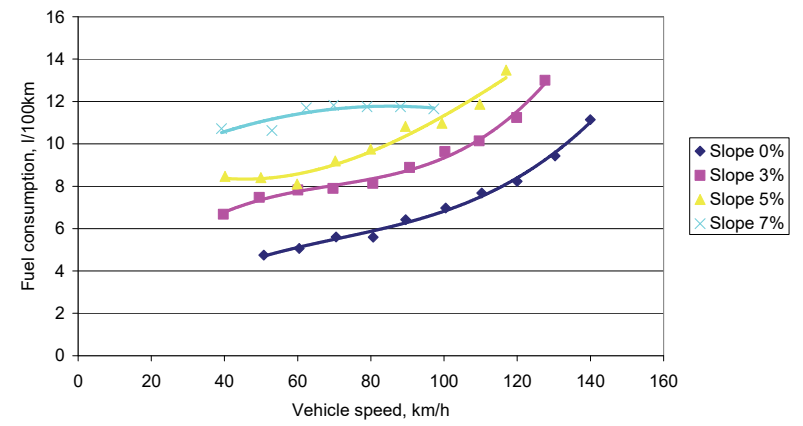

Fig. 14. Distance-based fuel consumption for gear IV and variable road inclination.

The summary of data regarding flow rate of fuel for a selected constant gearbox ratio, as visible on Fig. 15-18, demonstrates the considerable dependence of fuel consumption on the rotational engine speed and to a lesser degree relative to the increase of the road inclination. The greatest level of the change of the flow rate was noted for the 4th gear, where the consumption increased from around $3 \mathrm{l} / \mathrm{h}$ to $16 \mathrm{l} / \mathrm{h}$. For the $3 \mathrm{rd}$ gear, we noted a flow rate of fuel of $1.51 / \mathrm{h}$ (for $0 \% \mathrm{road}$ inclination corresponding to the rotational speed of 1500 rpm. However, an increase in fuel consumption is equal to as much as $6 \mathrm{l} / \mathrm{h}$ (i.e. from $6 \mathrm{l} / \mathrm{h}$ to $12 \mathrm{l} / \mathrm{h}$ ) for the rotational engine speed of $5000 \mathrm{rpm}$.

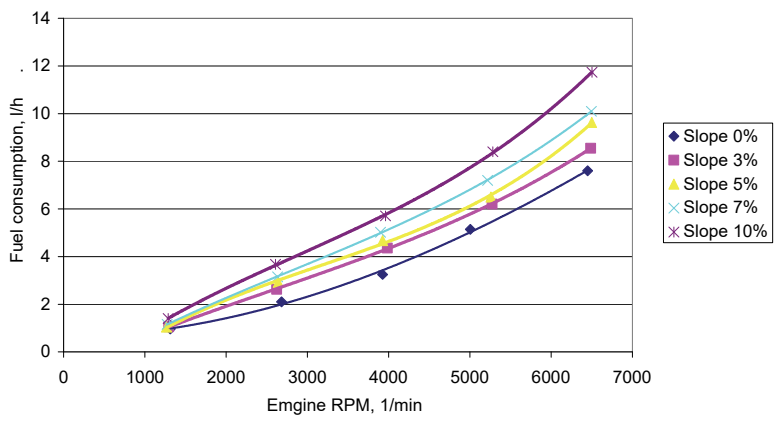

Fig. 15. Flow rate of fuel consumption of the engine for gear I and variable road inclination.

Hence, bearing in mind that the variable level of the engine load has such a considerable impact on fuel consumption, it is necessary to identify a gearbox ratio for which an operating point of the engine is maintained so as to achieve a maximum engine efficiency. For this reason, an important operating parameter applied to describe the characteristics of a transmission is associated with its overall efficiency. 


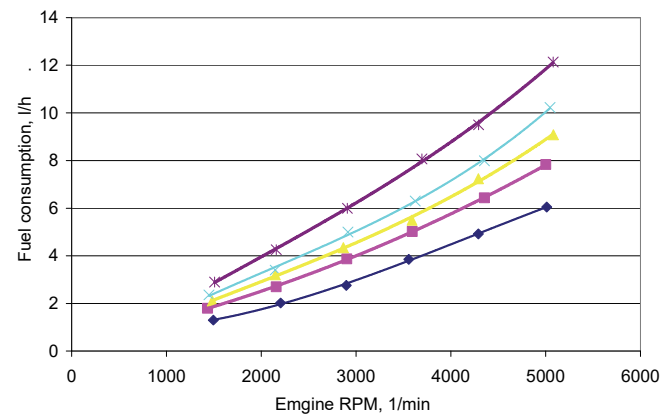

Fig. 16. Flow rate of fuel consumption of the engine for gear II and variable road inclination.
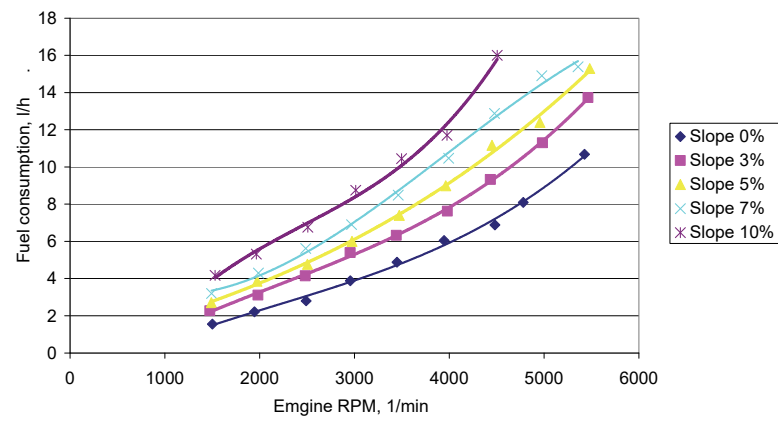

Fig. 17. Flow rate of fuel consumption of the engine for gear III and variable road inclination.

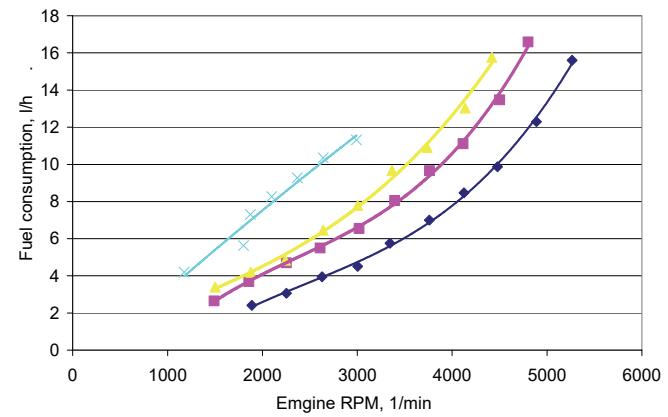

Fig. 18. Flow rate of fuel consumption of the engine for gear IV and variable road inclination.

On the basis of the analysis of the formula representing the overall engine efficiency (2), we can express it as the inverse of the product of the specific fuel consumption and its calorific value

$$
\eta_{o}=\frac{N_{e}}{G_{e} W_{d}}=\frac{1}{g_{e} W_{d}}
$$

Hence, the up-to-date powertrains are designed in such a manner that the engine is suitably matched to the drivetrain and the car gives the driver the freedom to select the linear car velocity by depressing the accelerator pedal, whereas the selection of the engine load and gearbox ratio is performed automatically. For this reason, the car applied in the study includes a multispeed automatic transmission.

Fig. 19, 20, 21, 22 presents the determined values of engine efficiency of the tested car, where the maximums of this parameter area are visible for each of the tested gearbox ratios and load levels. Thus, we can see that the maximum engine efficiency is in the range of $30 \%$ with a note that this level shifts from the 5 th gear to the 4 th one along with the increase in the load.

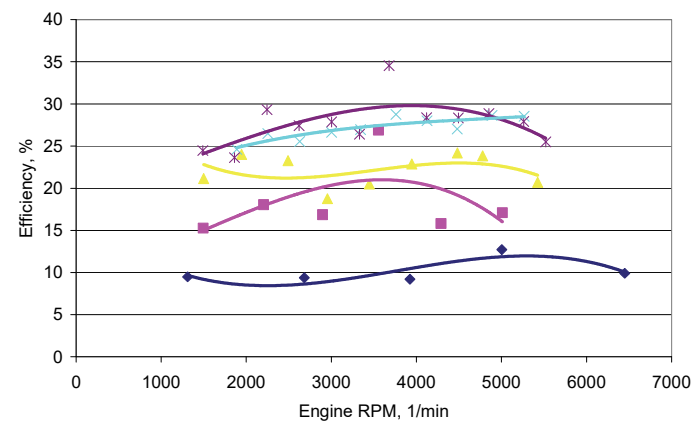

Fig. 19. Efficiency of the engine for $0 \%$ road inclination load and variable gearbox ratios.

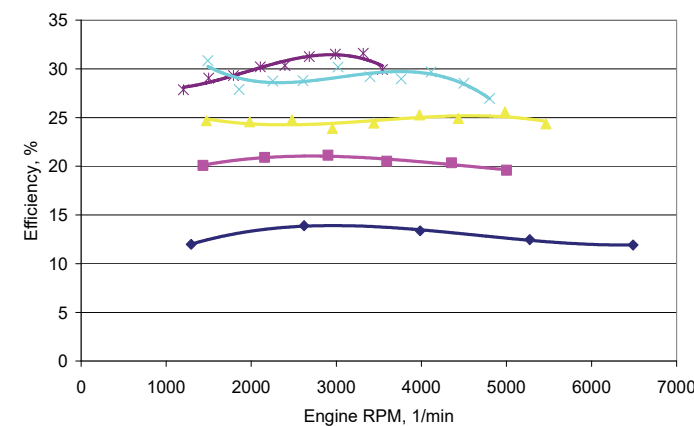

Fig. 20. Efficiency of the engine for 3\% road inclination load and variable gearbox ratios.

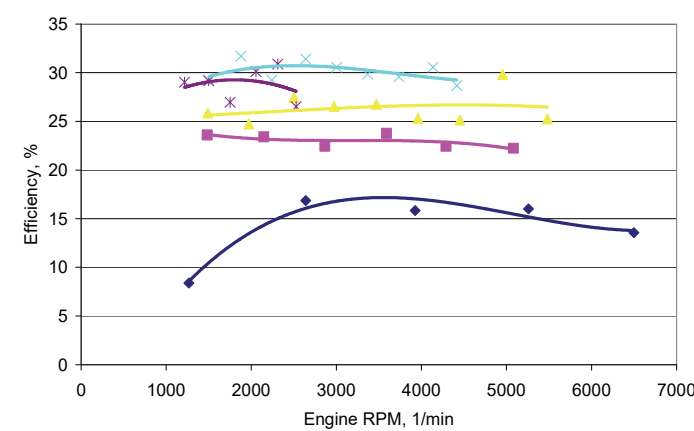

Fig. 21. Efficiency of the engine for $5 \%$ road inclination load and variable gearbox ratios.

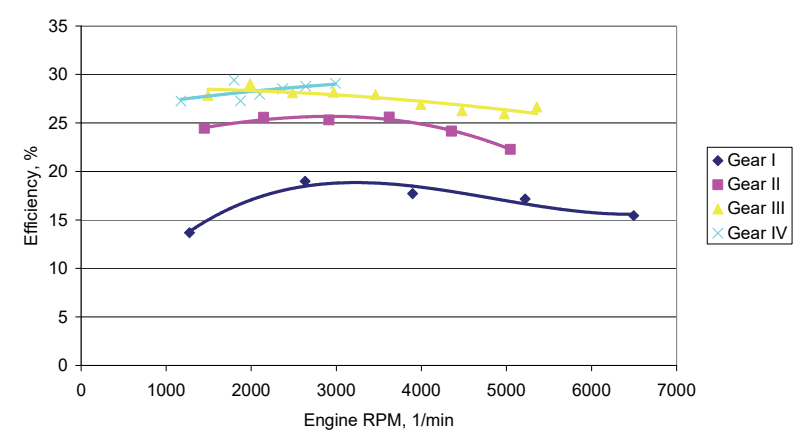

Fig. 22. Efficiency of the engine for 7\% road inclination load and variable gearbox ratios. 
Concurrently, the maximum engine efficiency can be noted for a horizontal road section in the conditions of a rotational speed of $4000 \mathrm{rpm}$, which shifts towards lower speeds for greater road inclinations, i.e. at $3 \% \mathrm{climb}-$ for the rotational speed of $3000 \mathrm{rpm}$, at $5 \%$ climb - for the rotational speed of $2500 \mathrm{rpm}$ (4th gear) and during $7 \% \mathrm{climb}$ - the rotational speed is already equal to 1800 rpm and the gear is 3rd. These are the areas for the operation of the engine with the greatest efficiency.

Accounting for the data from literature worldwide, we have to consider the tendency towards the greater automation of powertrain systems as a justified and correct one. Only in such conditions should we be able to select an operating point of an engine in an adequate manner to meet the demand with respect to the speed and load so that its maximum efficiency can be achieved.

\section{Conclusions}

The study conducted into powertrain characteristics leads to a clear statement that the fuel consumption and efficiency of a combustion engine in a passenger car are affected equally by the engine load resulting from the road inclination as well as the adequate selection of the gearbox ratio. The effect of the road inclination has an impact on the driver in terms of their response in the form of a greater depression of the accelerator pedal with the purpose of maintaining the required car speed as well as in the form of the selection of an adequate transmission ratio. The considerations above lead to a conclusion that in the conditions of a constant progress on the way to the improvement of the overall engine performance, it is important to find a manner in which the selection of an instantaneous operating point on engine characteristic is made so as to obtain an increase of the efficiency by selecting an adequate utilization rate of the power generated by the engine.

\section{References}

1. A. Bieniek, J. Jantos, J. Mamala, Transport 22, 247251 (2007)

2. E. Horvath, A. Torok, Production Engineering Archives 7, 6-10 (2015)

3. J. Mamala, Kompensacja niedostatku sity napędowej $w$ procesie rozpędzenia samochodu osobowego (Opole, 2011)

4. Transport Research Journal of Vilnius Giediminas XXII, 247-251 (2007)

5. M. Mitschke, Dynamika samochodu (WKL, Warszawa, 1972)

6. N. Reza, Jazar, Springer Science (New York, 2008)

7. J. Merkisz, J. Pielecha, S. Radzimirski, Springer Tracts on Transportation and Traffic 4, 1-170 (2014), DOI: 10.1007/978-3-319-02705-0

8. P. Lijewski, J. Merkisz, P. Fuc, A. Ziolkowski, L. Rymaniak, W. Kusiak, European Journal of Forest Research 136, 153-160 (2017), DOI: 10.1007/s10342-016-1015-2 